\title{
Breakdown in Nanofluids: A Short Review on Experimental Results and Related Mechanisms
}

\author{
M. G. Danikas \\ Democritus University of Thrace \\ Department of Electrical and Computer Engineering \\ Power Systems Laboratory, Xanthi, Greece \\ mdanikas@ee.duth.gr
}

\begin{abstract}
Nanofluids seem to gradually become an alternative to traditional insulating liquids, such as transformer oil. In this paper, a short review of experimental results as well as of possible breakdown mechanisms and of some of the factors affecting the breakdown strength of the said fluids is conducted. Most of the reports suggest that the addition of nanoparticles in insulating liquids improves the breakdown strength. However, some reports that contradict the above are also to be found. In view of this, an outline of future research is discussed. This review does not encompass all possible effects, parameters and factors affecting nanofluids but it is solely concerned with breakdown strength.
\end{abstract}

Keywords-nanofluids; breakdown strength; transformer oil; ester oil; partial discharges

\section{INTRODUCTION}

Traditional insulating liquids, e.g. transformer oils, have served well for many decades the high voltage industry. Alternative liquids such as, among others, silicone liquids are also used. Liquids are easy to fill a space, they can easily be circulated and they can dissipate heat. They have a satisfactory dielectric strength but, on the other hand, they can easily be contaminated from foreign particles, air bubbles etc.,. Contamination has as a result the decrease of their dielectric strength. Besides contamination other factors also play a role in affecting their dielectric strength. Factors such as area, gap spacing, liquid volume under stress, type of applied voltage, rate of applied voltage, play a vital role in determining the dielectric strength and, in general, the performance of an insulating liquid $[1,2]$.

Nanofluids have recently attracted the interest of the scientific and industrial community since they present good insulating properties and numerous people think them as an alternative to traditional insulating liquids. The basic new idea is that if insulating liquids are mixed with a certain percentage of nanoparticles, the thermal conductivity of the mixture increases and also the electrical properties are improved. It is the aim of the present short review to indicate aspects of traditional insulating liquids and also how such liquids can be improved with the addition of nanoparticles. It must be emphasized that the present review is not an exhaustive review on the parameters affecting the electrical behavior of nanofluids but it only concentrates on one basic quantity, that of their breakdown strength. It must be noted that in the context of the present work the terms "breakdown strength" and "dielectric strength" are used interchangeably.

\section{TRADITIONAL INSULATING LIQUIDS: GENERAL REMARKS}

Insulating liquids can fill any required space, they have a relatively low dielectric constant (about 2.2-2.3), relatively low dielectric losses, and - under certain conditions - they can recover their previous dielectric strength. An ideal insulating liquid must have, among others, high dielectric strength, low or high dielectric constant depending on the application, good thermal conductivity, low toxicity, good chemical stability and the appropriate viscosity $[1,2]$. Insulating liquids, however, are sometimes difficult to continue to have a high dielectric strength (especially if they have a large liquid volume) and they are easily contaminated (from foreign particles and air bubbles) [3]. Moreover, some of them presented high toxicity (e.g. PCB) and they have been removed from service. In industrial applications, such as in transformers, insulating liquids suffer from aging and all the consequences that entails [4].

Numerous publications refer to the factors affecting the dielectric strength of traditional insulating liquids. They all tend to some basic points: the dielectric strength of the insulating fluid decreases with the increase of the electrode area, with the increase of the gap between the electrodes, with the increase of the stressed liquid volume [5]. Other vital factors of a good performance of insulating liquids are the cleanliness of the electrodes, the cleanliness and the way of preparation of the liquid, i.e. the quality of the liquid, the conditioning process [6]. The most widely used insulating liquid is probably the transformer oil which is used in transformers, switching gear, capacitors etc. Transformer oil can age with time and it must be regularly checked in order to see whether its quality is still acceptable for further use. A variety of tests is available to researchers and utilities for this purpose. Transformer oil must be controlled regarding a whole series of tests w.r.t. its color, surface tension, dielectric strength, density, tan delta, diluted gaseous substances, resistivity etc. $[7,8]$.

Temperature is one of the factors influencing the electrical performance of transformer oil. Increase of temperature implies 
a decrease of its resistivity. Temperature affects the dielectric constant of transformer oil, especially if it has some traces of moisture. Increase of temperature means an increase in dielectric constant. Humidity has also a negative effect on the performance of the oil since it decreases its dielectric strength. Under certain conditions, traces of humidity cause breakdown channels [2]. It is imperative that humidity should not be allowed in transformer oil of industrial cleanliness . Foreign particles create the so-called particle bridges, which in turn facilitate the breakdown channels and consequently the breakdown. Such particle bridges are more conducting than the surrounding oil [9]. Air bubbles trapped in the oil are also a determining factor for the oil dielectric strength. Air bubbles, as having a lower dielectric constant than the oil, tend to elongate with increasing applied voltage. The larger the difference between the dielectric constants of air and oil, the smaller the required voltage for bubble elongation [10].

\section{BREAKDOWN IN CONVENTIONAL LIQUIDS}

According to weak link theory, the dielectric strength of transformer oil is as good as its weakest spot. This theory entails some statistical approach and there are numerous papers in this direction [11-14]. There has also been some discussions as to what sort of statistical distribution such a theory follows, extremal or normal $[5,15]$. Other theories were based on bubble elongation and subsequent breakdown [10]. Streamer theory has been followed in a number of papers [16]. Streamer theory is based on the notion that electrons are accelerated because of the applied voltage - and collide with liquid molecules, resulting thus in tine air pockets. Such tine regions are regions of low density. Such a low density region has a dielectric constant different from that of the surrounding liquid and a steamer will result. Such a streamer will expand towards the anode and will eventually cause breakdown in the liquid. Needless to say that such an emerging picture depends on the experimental conditions, such as the shape of the electrodes, the type of the applied voltage, the chemical constitution of the liquid and the hydrostatic pressure. Positive streamer having originated from the anode and going to the cathode seem to be more filamentary than the negative streamers. Both the positive and negative streamers seem to have four distinct modes of propagation [16].

\section{NANOFLUIDS}

Nanotechnology originally was proposed as an alternative to the solution of problems in [17]. Nanofluids as such were proposed in [18], who defined them as liquids having two phases: the conventional (that of the liquid) and nanoparticles (with dimensions between 1-100 nanom). Various types of nanoparticles were proposed as additives for the nanofluids. Nanoparticles may be classified as conducting, insulating and semiconducting. Biofluids, insulating oils, ethyl glycol etc. As were considered as base liquids. Nanofluids are colloid systems of two phases. A nanofluid must be stable, i.e. the nanoparticles must be evenly dispersed throughout the liquid, they must have prior treatment and they must not form agglomerations. Nanoparticles are expected to improve the electrical and thermal properties of the insulating liquids since - because of their small dimensions - have large interfacial area. Obviously, the interfacial zone increases dramatically by decreasing the particle size.

A nanofluid - being a colloidal system - must have thermodynamic stability and - depending on the relation between the attractive and repulsive forces among the nanoparticles - must avoid particle agglomerations. The behavior of a nanofluid can be explained with Tanaka's model developed in [19]. Originally, the model was proposed for polymer nanocomposites. However, as it is based on Colloidal Chemistry, it can also be applied to nanofluids. Nanoparticles are supposed to be covered by interfaces. Such interfaces are formed by chemical reactions of the surface of the nanoparticles with liquid molecules [20]. According to [19], nanoparticles consist of three layers, one tightly bonded with a thickness of about $1 \mathrm{~nm}$, the second bound layer of thickness of about 2-9 nm, and a third layer which is a loose layer of thickness of some tens of nm. It is the third layer that comes into contact with the surrounding base material and it creates the interface between the nanoparticle and the base material. It is true that originally this model was proposed for polymer nanocomposites but it can also be applied to nanofluids (a detailed descriptions of several nanocomposite models are given in [21-24]). Actually the principles are the same, in the case of the nanofluids since we have again nanoparticles surrounded by a base material.

One should not forget, however, that in the case of the nanofluids there is a larger and freer nanoparticle movement than in the case of the polymer nanocomposites. In fact, that model model must have inspired another model based on EDL (electric double layer). In [25], it was reported that "according to the electric double layer (EDL) theory, when the nanoparticles surface is in contact with transformer oil, the free charge in the oil will be attracted to the nanoparticles surface. The static charge on the nanoparticles surface will attract the counter-ions and repel the co-ions in the transformer oil. The charges on the particles surface and the re-arranged ions in the oil form the EDL. Immediately next to the charged nanoparticles surface, there is a layer of counter-ions that are strongly attracted to the particles surface and are immobile. This layer is called the compact layer. From the compact layer to the electrically neutral transformer oil, the net charge density reduces to zero gradually. Ions in this region are affected less strongly by the electrostatic interaction and are mobile. This region is called the diffuse layer of the EDL".

There are three basic methods to produce nanofluids. The Eastman method is a one-step method which produces and disperses nanoparticles in the base fluid simultaneously. A disadvantage of this method is that it has a high cost and there may be byproducts remaining in the nanofluid because of insufficiently completed chemical reactions [26]. Another method is a two-step method, in which nanoparticles initially form a nano-powder and then a mixture with the base fluid follows with the aid of ultrasonic agitation, with high shear mixing, homogenization and ball milling. It is a lower cost method since it is used now also for industrial purposes. It requires, however, that the nanoparticles are treated so that they do not form agglomerations [27]. A third method is that of submerged arc nanoparticle synthesis system (SANSS) [28]. 


\section{EXPERIMENTAL DATA REGARDING THE BREAKDOWN IN NANOFLUIDS}

The alteration of the nanoparticles' surface is a good and economic way to reinforce the stability of nanofluids. Surfactants (or coupling agents) have a significant influence upon the interface region between the nanoparticle and the base liquid. Surfactants must be chosen in such a way that they must be well dispersed in the insulating oil. Their quantity must be appropriate. In any other case, the use of a large quantity of surfactants may cause weak links between the nanoparticles and the base liquid.

\section{INFLUENCE OF SHALLOW TRAPS ON THE BREAKDOWN OF NANOFLUIDS HAVING AS BASE LIQUID THE TRANSFORMER OIL}

Nanofluids which have as a base liquid the transformer oil and nanoparticles $\mathrm{TiO}_{2}$ present higher dielectric strength than that of plain transformer oil. In the nanofluid there is a large density of shallow traps. Electrons may change their velocity to lower values because of the shallow traps and consequently the dielectric strength may increase [29]. Another explanation of the improvement of dielectric strength was given in [30], where it was remarked that if the relaxation time constant of the [conducting] nanoparticles is small in comparison with the time development of a streamer in the nanofluid, then this can have an influence on the breakdown strength. If, on the other hand, the relaxation time constant is far too large, then it will have small effect on the streamer development. The charge relaxation time constant for the nanoparticles can be given as:

$$
\tau=\frac{2 \varepsilon_{1}+\varepsilon_{2}}{2 \sigma_{1}+\sigma_{2}}
$$

where, $\varepsilon_{1}$ and $\sigma_{1}$ are the permittivity and conductivity of the liquid insulation, $\varepsilon_{2}$ and $\sigma_{2}$ are the permittivity and conductivity of the nanoparticles. Initially, there was the thought that conducting magnetic nanoparticles may capture the free electrons required for the streamer development and they could transform them into slower negatively charged particles because their relaxation time constant was much smaller than the time development of the streamers [30]. However, there were also indications that a certain kind of conducting nanoparticles with small relaxation time constant did not substantially increase the dielectric strength of the nanofluid in comparison with that of the transformer oil [31].

It has been observed that the addition of magnetic nanoparticles into transformer oil increased the breakdown strength of the resulting nanofluid $[32,33]$. It is possible that the increase in dielectric breakdown voltage with the added magnetic nanoparticles to transformer oil might be because the conductive nanoparticles affect as electron scavengers in electrically stressed transformer oil-based nanofluids and change fast electrons into slowly negative charged nanoparticles for the electrical breakdown. To express it in other words, the extension of a net space charge zone at the streamer tip is hindered due to the slowly mobility of negative charged nanoparticles, and it is suppressed to the generated streamer propagation in the transformer oil for electric field propagation wave. The above publications confirmed previous experimental data on magnetic colloidal fluids found in [34] (full theory given in [35]). Even minute additions of magnetic nanoparticle volume concentrations may substantially increase the breakdown strength of a nanofluid in comparison with the pure transformer oil (about 30\% higher). Similar results with magnetic nanoparticles have been reported in [36]. The latter, however, warned about the dangers of nanoparticle agglomeration and its negative effects upon the breakdown strength of nanofluids. Lower increases in breakdown strength have been recorded with somehow larger volume concentrations of magnetic nanoparticles with lightning impulse voltages [37]. The reason as to why lightning impulse breakdown voltage is higher in the nanofluids was again traced to the very nature of the added nanoparticles, namely that they act as electron scavengers.

The question as to whether addition of nanoparticles causes an increase or decrease of the breakdown strength was treated in [38], where it was shown that an increase or decrease depends on the nature of the added nanoparticles. According to [38] the dielectric strength of the transformer oil decreases substantially with increasing the nanoparticle volumetric concentration for multiwalled carbon nanotubes and diamond nanoparticles. Very recently [39], it was noted that transformer oil-based nanofluids (with $\mathrm{TiO} 2$ nanoparticles) present a higher breakdown strength than pure transformer oil under moisture conditions, the improvement being even larger as the moisture content is higher. In fact, as was reported, the breakdown voltage of the nanofluid at $1 \%$ probability of failure is $15.8 \%$ higher than that of the pure oil when the moisture content is 12 ppm, whereas the improvement of breakdown strength raises to $305.8 \%$ as the moisture content reaches $42 \mathrm{ppm}$. The authors contributed this increase in breakdown strength to the hydrophilicity of the $\mathrm{TiO}_{2}$ nanoparticles, which can bind more dissolved water and other impurities in oil, as their size gets smaller and smaller. The bound water cannot be moved by the electrical field hereby devoting little to the breakdown process. For this reason, the AC breakdown strength and dispersion of $\mathrm{TiO} 2$ nanofluids are much better than pure transformer oil with high moisture contents. The same group of authors [40] investigated mineral oil based nanofluids with various types of nanoparticles ( $\mathrm{Fe} 3 \mathrm{O}_{4}, \mathrm{TiO}_{2}$ and $\mathrm{Al}_{2} \mathrm{O} 3$ ) employing positive lightning impulse voltages. They contributed the obtained higher breakdown strength in nanofluids to the trappingdetrapping of electrons due to the presence of the nanoparticles. The aforementioned authors realized that some differences exist as to the ability of different types of nanoparticles to contribute to the rise of the breakdown strength and they attributed this not only to the type of the nanoparticles but also to the interfacial characteristics between nanoparticles and transformer oil. The same approaches as to the breakdown mechanisms in nanofluids were also expressed in an earlier publication by the same group of authors [41].

The importance of nanoparticles for the breakdown strength of nanofluids was emphasized in [42], where magnetic nanoparticles, such as $\mathrm{Fe} 3 \mathrm{O} 4$, were dispersed in transformer oil. The authors attributed the improvement of the breakdown strength to the trapping-detrapping processes which delay the breakdown mechanism, to reduced space charge densities which in turn lead to more uniform electric fields distribution. There was, however, in the same paper also a warning against nanoparticle agglomerations. On the mechanism of scavenging 
charge, also reported in [43], the authors of which also pointed out that above a critical concentration of nanoparticles, the inter-particle distance is reduced to the point wherein the liberated charges can traverse through the particle, and 'flight' on the next particle due to the intimacy and/or direct contact and reach to the opposite streamer zone. The percolation chains thereby act as agents that induce 'merger' of the streamers, often leading to numerous intermittent arc discharge and eventually leading to reduced breakdown strength. Commenting on the same lines, the author of [44] pointed out that there are clearly two contrasting phenomena which are at work: charge injection and trapping occurs up to a certain nanoparticle concentration, whereas at higher nanoparticle concentrations the distance between the nanoparticles becomes too small and secondary charge emission may "bypass" the trapping behavior of nanoparticles and increase the global conductivity.

Addition of plasma surface treated $\mathrm{SiO}_{2}$ nanoparticles into transformer oil in minute quantities $(0.05 \mathrm{wt} \%$ and $0.1 \mathrm{wt} \%)$ greatly improves the breakdown strength of transformer oil. The authors of [45] claimed that instead of using surfactants, atmospheric pressure plasma treatment is an effective, simple, inexpensive and environmentally friendly method to improve the stability of nanofluids and enhance the characteristics of the nanofluids as well. Addition of $\mathrm{SiO}_{2}$ nanoparticles into a soya based natural ester oil also raised the breakdown voltage significantly (the $0.01 \mathrm{wt} \%$ concentration virtually tripled the breakdown voltage of ester oil without nanoparticles) [46]. Moreover, the same authors presented data which showed that the partial discharge inception voltage of such nanofluids was higher than that of pure soya based natural ester oil [47]. There was further elaboration of the above in yet another paper, again with the use of $\mathrm{SiO}_{2}$ nanoparticles [48], with the authors emphasizing the negative effects of nanoparticle agglomeration. They noted that while they moved from $0.05 \mathrm{wt} \%$ to $0.1 \mathrm{wt} \%$ concentration the electrical performance of sunflower oil started to decline.

However, there were also reports that indicated that breakdown strength does not improve with the addition of nanoparticles (in particular with nanoparticles $\mathrm{SiC}$ ). Such nanoparticles, on the contrary, decreased the breakdown strength of transformer oil [49]. The same authors concluded that, in view of such data, more experiments should be done, since some of the experimental results seem to be contradictory. The fact that there is not always an improvement in nanofluids breakdown strength was also stressed in [50], the authors of which investigated virgin linseed and virgin castor oil with $5 \mathrm{wt} \%$ addition of silica aerogel powder nanoparticles. They found that nanomodification increased streamer activity in the vegetable oils. The increased streamer activity was more aggressive in nanomodified castor oil than in nanomodified linseed oil. They proposed as a possible explanation for this the possible presence of contaminants left by a filler compatibilisation process which can worsen the electrical properties of a nanostructured material. Authors in [51], it was noted that nanoparticles such as $\mathrm{Fe} 3 \mathrm{O} 4, \mathrm{ZnO}, \mathrm{TiO} 2, \mathrm{SiO} 2$, improved the AC breakdown strength of transformer oil in volumetric concentrations ranging from $0.0005 \%$ up to $0.02 \%$. They pointed out the vital role of an appropriate surfactant for the breakdown strength improvement. Regarding DC breakdown as well as impulse breakdown, they noted that results were encouraging for both polarities. Experimental work performed by the authors of [52] showed that nanoparticles of $\mathrm{ZnO}$ with $0.04 \%$ volumetric concentration may give up to $63.5 \%$ enhancement in breakdown voltage compared with pure transformer oil. The authors remarked that there is an optimum concentration of nanoparticles which may give high breakdown voltage as well as high fire and flash points. Experimental data was also produced in [53], where $\mathrm{ZnO}$ nanoparticles of $0.2 \mathrm{wt} \%$ up to $1 \mathrm{wt} \%$ were added into transformer oil. The breakdown voltage increased by about $10 \%$ in comparison with the pure transformer oil. It must, however, be noted that the nanofluid with more than $0.4 \mathrm{wt} \%$ concentration showed an increase in electrical conductivity.

A very recent development proposes transformer oil-based graphene quantum dots nanofluids [54]. However, as far as the breakdown strength is concerned, there was not any significant difference between pure transformer oil and its transformer oilbased nanofluid. The difference was minimal, such as not to warranty any replacement of transformer oil with the nanofluid, at least regarding the breakdown strength. In [55], it was indicated that carbon nanotubes, when dispersed in transformer oil, can increase substantially the breakdown voltage. In fact, it was shown that a concentration of $0.01 \mathrm{~g} / \mathrm{L}$ carbon nanotubes may increase the breakdown voltage as much as $88.95 \%$ compared with the pure transformer oil. The authors also emphasized that there is a saturation point, after which the addition of carbon nanotubes does not improve the breakdown voltage but on the contrary may diminish it. Transformer oil with nanoparticles of $\mathrm{TiO}_{2}$ was investigated in [56]. The author worked by adding $\mathrm{TiO} 2$ nanoparticles at a concentration of $0.0005 \mathrm{~g} / \mathrm{ml}$. The increase in breakdown voltage w.r.t. that of pure transformer oil was attributed to either the fact that polarized $\mathrm{TiO}_{2}$ nanoparticles can act as electron traps to catch free electrons released from oil molecules under high electric stresses or to the higher chance of electron scattering in nanofluids due to the high specific surface area of nanoparticles.

Deviating from the usual added nanoparticles, a research team proposed the admixture of nanocrystalline manganese nickel ferrite powder concerning substitution degree of $20 \%$ (Mn0.2Ni0.8 $\mathrm{Fe} 2 \mathrm{O} 4)$ into transformer oil at different concentrations of $0.02,0.04$, and $0.06 \mathrm{~g} / 1$ [57]. The experiments were carried out with impulse voltage and the authors found that the optimum concentration was that of $0.04 \mathrm{~g} / 1$, which gave a breakdown voltage improvement of $42.3 \%$ as opposed to improvements of $37.7 \%$ and $39.1 \%$ for the $0.02 \mathrm{~g} / 1$ and $0.06 \mathrm{~g} / 1$ concentrations respectively. The authors, however, did not mention anything as to the stability of such mixtures in the long run. In [58], transformer oil with $\mathrm{MgMnNi}$ nanoparticles were investigated regarding its breakdown strength (in some cases it almost doubled the breakdown strength in comparison with pure transformer oil]. The authors attributed the increase to the enhanced electric field dissipation due to the presence of magnetite nanoparticles. In [59], $\mathrm{MgMnNiFe}_{2} \mathrm{O}_{4}$ nanoparticles were dispersed in transformer oil ( $<1 \%$ by volume) improving by about $40 \%$ the breakdown strength in comparison with pure transformer oil. 
Diamond nanoparticles dispersed in small concentration $(0.15 \mathrm{wt} \%)$ into transformer oil may raise the breakdown voltage considerably. The reason given in [60] was not any different from that given in other publications, namely that nanoparticles act as surface traps and, consequently, they can entrap the surface electrons. The fast electrons change to the slow ones, and subsequently an increase in the breakdown voltage results. Although the explanation may not be entirely novel, the authors commented on the importance of surfactants for the nanoparticles and their influence not only on the breakdown voltage but also on viscosity, dielectric loss and thermal conductivity. The role of surfactants was also emphasized in [61], where it was shown that the surfactant volumetric concentration may be $40 \%$ of the complete nanoparticle volume. The authors showed that there is a strong dependence of the breakdown strength of a vegetable oil-based nanofluid on the nanoparticle size as well as on the thickness ratio between the nanoparticle diameter and that of the surfactant. It seems that smaller surfactant thickness offers more shallow traps and consequently a greater chance of electron trapping-detrapping. In [62], the AC breakdown voltage as well as the positive lightning impulse breakdown voltage of mineral oil-based nanofluids with alumina were shown to be higher than the respective quantities of the pure transformer oil. The authors, however, did not further elaborate as to why this should be so. $\mathrm{SiO}_{2}$ nanoparticles were added to transformer oil in concentrations of up to $0.06 \%$ volume fraction and the AC breakdown voltage increased considerably up to $35 \%$ compared with pure transformer oil [63]. A further increase, however, of the nanoparticle concentration leads to a decrease of the breakdown voltage of the nanofluids. Higher concentration may lead to the overlap of nanoparticles making thus a highly conductive region. The free charge will travel along the high conductive path and this process may cause a lower breakdown voltage.

Palm fatty acid ester (PFAE) oil with three types of nanoparticles at a concentration of $0.01 \mathrm{~g} / 1\left(\mathrm{Fe}_{3} \mathrm{O}_{4}\right.$ conductive nanoparticles, $\mathrm{TiO}_{2}$ semi-conductive nanoparticles and $\mathrm{Al}_{2} \mathrm{O}_{3}$ insulating nanoparticles) was been tested in [64]. The nanofluid with the $\mathrm{Fe}_{3} \mathrm{O}_{4}$ conductive nanoparticles presented the highest AC breakdown strength (an increase of $45 \%$ compared to $29 \%$ for $\mathrm{TiO}_{2}$ nanoparticles and $34 \%$ for the $\mathrm{Al}_{2} \mathrm{O}_{3}$ nanoparticles). The explanation regarding the improvements of the breakdown strength was attributed for the conductive nanoparticles to their electron scavenging capability, and to the semi-conductive and insulating nanoparticles to their shallow trap production. $\mathrm{Fe}_{3} \mathrm{O}_{4}$ nanoparticles were dispersed in transformer oil at volume concentrations of $0.1-0.6 \%$, with the impulse lightning voltage being the highest at about volume concentration of $0.3 \%$ [65]. Other researchers [66] experimented with $\mathrm{AC}$ voltages as well as with positive and negative lightning impulses in nanofluids having $\mathrm{Fe}_{3} \mathrm{O}_{4}$ nanoparticles. They found that the $\mathrm{AC}$ breakdown voltage was by $16 \%$ higher than that of the pure transformer oil, the positive lightning impulse breakdown voltage by $36 \%$ higher than that of the pure transformer oil and the negative lightning impulse breakdown voltage by about $20 \%$ higher. They attributed such large differences to the well known theory developed in [67], according to which if the relaxation time constant of free charges accumulated on the surface of nanoparticle is shorter than the time scale of streamer propagation, the presence of nanoparticles will effectively alter the electrodynamics in the oil.

Yet another group of researchers dispersed $\mathrm{TiO} 2$ nanoparticles in transformer oil [68]. The concentrations of $\mathrm{TiO}_{2}$ nanoparticles in transformer oil are in the range from $0.001 \mathrm{~g} / \mathrm{L}$ to $0.01 \mathrm{~g} / \mathrm{L}$. The optimum concentration was about $0.003 \mathrm{~g} / \mathrm{L}$ for both fresh and aged transformer oils (4 and 15 years aged oils). They attributed the improvement -as others before them - to the electron scavenging properties of the nanoparticles. Dispersion of $\mathrm{TiO}_{2}$ nanoparticles in transformer oil in quantities of 0.05 up to $0.30 \mathrm{~g} / \mathrm{L}$ and their effects on the breakdown strength was reported in [69]. The largest breakdown voltage was observed for $0.30 \mathrm{~g} / \mathrm{L}$ concentration of $\mathrm{TiO}_{2}$ nanoparticles. In a later publication, the same authors [70] reached the same conclusions, emphasizing the important role the surfactants play in the dispersion of nanoparticles. No surfactant or low surfactant concentration leads to nanoparticle agglomeration but, on the other hand, excess of surfactant concentration leads to double chains around the nanoparticles reducing thus their effectiveness. More recently, authors in [71] experimented with natural-ester transformer oil by adding $\mathrm{CuO}, \mathrm{ZnO}$ and $\mathrm{TiO}_{2}$ nanoparticles. The breakdown voltage with the two latter types of nanoparticles was greatly improved (with concentration of less than $0.05 \mathrm{wt} \%$ ), whereas the nanofluid with $\mathrm{CuO}$ nanoparticles showed at first an increase in the said quantity and then a decrease. With concentration of more than $0.1 \mathrm{wt} \%$ the breakdown voltage did not improve as far as the nanofluids with $\mathrm{ZnO}$ and $\mathrm{TiO}_{2}$ nanoparticles were concerned. From this publication it is evident that different types of nanoparticles with different added percentages affect differently the breakdown voltage of an insulating oil. The explanation of the authors as to why such an improvement results does not differ from that of other researchers. Added $\mathrm{TiO}_{2}$ nanoparticles into natural ester fluid (nanoparticle content $0.4 \mathrm{~g} / \mathrm{l}$ ) improved its breakdown voltage, especially after 150 hours of ageing [72]. The authors of [72], however, posed questions as to the long-term stability of such nanofluids. Some other researchers experimented with soybean ester oil and palm ester oil with $\mathrm{TiO}_{2}$ and $\mathrm{ZnO}$ nanoparticles [73]. Both oils showed a higher AC breakdown voltage with $0.2 \mathrm{~g} / 1$ nanoparticles (of either type). The explanation they offered as to the higher breakdown voltages with the nanofluids was not different from those of other scientists. It is to be noted, however, that increasing amounts of nanoparticles seem to have negligible effect on the flash point, fire point and viscosity [73]. Thus, nanofluids have to be considered in all their properties before a final decision has to be made about the replacement of the more classical insulating liquids.

An interesting aspect of Tanaka's model (which was proposed for polymer nanocomposites) was tackled in [74]. The authors tried to explain the superior breakdown strength of natural ester oil with Boron Nitride nanoparticles (with content of $0.005 \mathrm{wt} \%$ and $0.1 \mathrm{wt} \%$ ) in terms of Tanaka's model, namely that with the decrease in size of the nanoparticles the interfacial regions become very important and they alter the charge distribution causing thus change in trap density and depth. The homocharge due to trapping reduces the electric field intensity and causes an increase of the voltage for charge 
injection from the electrodes. This in turn causes the increase of the short term breakdown voltage. A point of contention in this paper is certainly the claim that there is an increase of the short term breakdown voltage. This, however, will be discussed in the following section. An improvement of the $\mathrm{AC}$ breakdown strength as well as of the positive lightning impulse strength (but not of the negative lightning impulse strength) of vegetable oil with $\mathrm{Fe}_{3} \mathrm{O}_{4}$ nanoparticles was reported by [75]. The remarkable about this paper is that the authors attribute the higher breakdown strength of nanofluids to the larger electrical potential wells of nanoparticles in comparison with the ones of the pure insulating liquid. They also mention that the electrical potential wells are larger as the nanoparticle size becomes larger. Such electrical potential wells inhibit the free charge spread and enhance the capability of the breakdown performance of the nanofluids.

Work carried out with natural ester based nanofluids (with Commercial MIONs Powder (pNF) and Oleic Acid Surface Modification, as well as with Oleate-Coated Colloidal MIONs (colNF)) showed that breakdown voltage was the highest with the colNF at a concentration of about $0.008 \mathrm{wt} \%$ ). The authors attributed the decrease of the breakdown voltage after the surpassing of the $0.008 \mathrm{wt} \%$ concentration to the [76] to the decreasing of interparticle distance and the formation of conductive paths. The positive influence of nanoparticles $\left(\mathrm{SiO}_{2}, \mathrm{TiO}_{2}, \mathrm{ZnO}, \mathrm{Al}_{2} \mathrm{O}_{3}, \mathrm{Fe}_{3} \mathrm{O}_{4}\right.$ and $\left.\mathrm{SiC}\right)$ in transformer oil and in natural ester oil was reported in [77]. The authors emphasized the importance of moisture in diminishing the breakdown strength in both types of oil. Similar conclusions regarding the positive effect of $\mathrm{SiO}_{2}$ hydrophilic nanoparticles were reached in [78], where, however, it was also remarked that their positive influence depended on their size and their volume concentration. Similar conclusions regarding the moisture absorption on the hydrophilic surface of silica nanoparticles have been reached in [79]. Nanoparticles of $\mathrm{Fe}_{3} \mathrm{O}_{4}$ added to transformer oil in volume concentration of $0.2 \%$ raise the DC breakdown voltage in comparison with pure transformer oil [80]. Such nanoparticles affect negatively the formation of bubbles and because of their extremely short charging time, they are excellent electron traps.

A criticism levelled against the use of conductive nanoparticles was reported in [81], where it was mentioned that conductive nanoparticles tend to agglomerate in the long-term and nanoparticles such as $\mathrm{Fe}_{3} \mathrm{O}_{4}$ tend to oxidize and become $\mathrm{Fe}_{2} \mathrm{O}_{3}$ particles. The author of [81] proposed that nanoparticles such as $\mathrm{TiO}_{2}$ and $\mathrm{BN}$ offer better possibilities to both mineral oil and ester based oils. The aforementioned nanoparticles in minute quantities improved the $\mathrm{AC}$ breakdown voltage and also the lightning impulse voltage of the said oils. Adding nanoparticles of $\mathrm{TiO}_{2}$ and $\mathrm{ZnO}$ (in concentration of $0.01 \mathrm{wt} \%$ ) into natural ester oils improved the AC breakdown voltage as well as the lightning impulse (both positive and negative) [82]. The authors of the latter publication distinguished between adding nanoparticles in liquid form and in powder form and they observed that the nanoparticles in liquid form gave the highest breakdown voltage, probably because of the better dispersion in liquid form. An improvement in breakdown strength was noted for both AC voltages and lightning impulse voltages. Other researchers [83] investigated nanofluids based on transformer oil and on synthetic ester oil with $\mathrm{SiO}_{2}$ nanoparticles. The increased lightning impulse breakdown voltage - with volume concentrations from $0.1 \%$ up to $1 \%$ they found was attributed to the hydrophilic nature of the $\mathrm{SiO}_{2}$ nanoparticles and their altered degree of polarization. (Researchers exploring various nanoparticles in mineral oil found that $\mathrm{Al}_{2} \mathrm{O}_{3}$ and $\mathrm{TiO}_{2}$ nanofluids remain good insulating liquids as far as their dielectric constant and loss tangent are concerned but they expressed their reservations as to the long term insulating properties over a broad range of frequencies $(20$ $\mathrm{Hz}-1 \mathrm{MHz}$ ) because of water absorption from hygroscopic nanoparticles [84]).

An improvement of breakdown strength of aged transformer oil by adding nanoparticles of either $\mathrm{ZnO}$ or $\mathrm{TiO}_{2}$ in volume concentrations $\mathrm{w} / \mathrm{v} \%$ of $0.001 \%, 0.0015 \%$, and $0.002 \%$ was observed in [85]. 10- and 20- year old oils were treated with nanoparticles and showed a satisfactory recovery in breakdown strength. Similar conclusions about the beneficial effect of $\mathrm{TiO}_{2}$ nanoparticles on the breakdown voltage and the insulation resistance of mineral oil (in concentrations of 0.06 $\mathrm{g} / \mathrm{l})$ were recently reached also in [86]. Recently [87], there were reports about the improvement of ester oil breakdown voltage with egg shell nanoparticles in $0.0 .001 \mathrm{wt} \%$, $0.0025 \mathrm{wt} \%$ and $0.005 \mathrm{wt} \%$ concentrations. The highest breakdown voltage was noted for $0.005 \mathrm{wt} \%$ and it was attributed to the fact that such nanoparticles can absorb moisture. The authors reported stability of the nanofluid up to 48 hours without the formation of any precipitate/particles sedimentation. However, there are cases where the breakdown strength of transformer oil does not increase. Recent work [88] indicated that Tungsten (III) Oxide (WO3)-silver nanoparticles in concentration of $1 \mathrm{wt} \%, 2 \mathrm{wt} \%$ and $3 \mathrm{wt} \%$ decreased the breakdown strength compared with that of pure transformer oil. Perhaps the electrical conductivity of silver particles contributed to that decrease.

\section{PROPOSALS FOR FUTURE RESEARCH}

From the limited survey presented in this paper, it is clear that most of the researchers agree on the reasons of the improvement of the breakdown strength of nanofluids, i.e. on the workings of the mechanism which renders nanofluids superior to their respective base liquids. From the literature survey, it is evident that the concentration of nanoparticles into base insulating liquids depends on the oil itself, on the type of nanoparticles, on the surfactants and on the treatment, i.e. the way of preparation of the nanofluids. Experimental data seems to be very sensitive to all the previous parameters. Consequently, more work has to be done in the materials direction in order to better understand the properties of nanofluids and their effect on breakdown strength, especially in the light of some contradictory results, as reported in [89] and in [90]. The authors of the latter publication make the distinction between conducting, semiconducting and nonconducting nanoparticles claiming that the latter are more benign than the two former types of nanoparticles. Furthermore, more work has to be performed in the direction of high and low dielectric constant nanoparticles since, according to recent research, it seems that the former tend to better trap 
and de-trap electrons, whereas the latter do not have the ability for electron attraction [91].

Among the things that remain to be seen and investigated, is whether the Tanaka model (proposed for solid nanocomposites) is also valid for nanofluids. This point can be further elaborated: since Tanaka's model seems to work for solid dielectrics - nanoparticles act as nano-barriers against the treeing etc. - and nanoparticles in nanofluids seem to attract free electrons and thus hinder streamer propagation, it would be of interest to see whether Tanaka's model can find an application also in nanofluids. Other nanomaterial models, such as those mentioned in [22], can also be tested for their validity in the field of nanofluids. Breakdown studies in solid dielectrics show that nanoparticles act as barriers which hinder treeing and breakdown. Breakdown studies in liquids, however, emphasize more the scavenging effects of nanoparticles. Based on this difference, we think that Tanaka's model has to be modified somehow in order to take into account the scavenging possibilities of the nanoparticles. Whether this is a right idea must be further explored. Moreover, what has been done for classical insulating liquids (i.e. experiments with area effect, gap effect, volume effect, conditioning phenomenon) must also be performed with nanofluids. In traditional insulating liquids there has been an intensive study of such factors upon the breakdown strength. Similar studies must be carried out for the nanofluids. Statistical studies (based either on Weibull or on any other distribution) should be done in order to see whether nanofluids follow also the pattern of the classical liquids (although it seems that most of the researchers tend to work with Weibull distribution). The effect of nano-agglomerations needs also a closer look. The role of surfactants has to be thoroughly researched [92]. A question in need of an urgent answer is that of the long-term stability of nanofluids [44]. The already reported improvement of nanofluids - regarding their breakdown strength - because of electron scavenging from the nanoparticles, needs to be investigated in the long run and see whether experimental results are repetitive.

Another aspect of the nanofluids that has to be further researched is the compatibility of such liquids with solid insulation. Given that the nanofluids present a somehow different dielectric constant from the base liquids, the question that arises is whether such difference in dielectric constants (between nanofluids and air pockets or voids) renders the use of such liquids more difficult. Important work already done in relevant areas has to continue [93]. Furthermore, nanoparticle research has to be performed with vegetable derived fluids or synthetic esters, which are supposed to have a more "green" behavior (such research is being already done but it has to be intensified). Another aspect of nanofluids that has to be researched is their behavior at elevated temperatures. Last but not least, and this is valid for all nanomaterials, the insulation community has to see how laboratory experiments and data can be translated into larger samples of industrial sizes. Concerns as to how this can be realized have already been expressed [94]. Needless to say that all the above can be realized under the assumption that adequate funding is and will be available [95].

\section{CONCLUSIONS}

This publication is a short review on the breakdown of nanofluids. A large number of researchers converges as to the mechanism of breakdown in a nanofluid. Nanoparticles seem to have a scavenging role regarding the free electrons and as a consequence a higher breakdown strength results. However, in the context of this paper, only one aspect has been somehow been approached. Other aspects of nanofluids, such as viscosity, thermal properties, dissipation factor etc. merit also the appropriate attention. It is true that a great deal has been done regarding the research on nanofluids. A great deal more has to be done. Last but not least: the long-term stability of nanofluids has to be meticulously researched since this aspect is perhaps the most basic aspect for large scale industrial applications.

\section{REFERENCES}

[1] D. F. Binns, "Breakdown in liquids", in: Electrical Insulation, pp. 15-32, Peter Peregrinus Ltd, London, UK, 1983

[2] A. Kallinikos, "Evaluation of liquid insulants", in: Electrical Insulation, pp. 178-196, Peter Peregrinus Ltd, London, UK, 1983

[3] J. L. Maksiejewski, H. Tropper, "Some factors affecting the measurement of the electric strength of organic liquids", Proceedings of IEE, Vol. 101, pp. 183-190, 1954

[4] M. G. Danikas, Factors affecting the breakdown strength of transformer oil, M. Sc. Thesis, University of Newcastle-upon-Tyne, Department of Electrical and Electronic Engineering, 1982

[5] W. R. Bell, "Influence of specimen size on the dielectric strength of transformer oil", IEEE Transactions on Electrical Insulation, Vol. 12, No. 4, pp. 281-292, 1977

[6] M. G. Danikas, "Breakdown of transformer oil", IEEE Electrical Insulation Magazine, Vol. 6, No. 5, pp. 27-34, 1990

[7] S. Missas, M. G. Danikas, I. Liapis, "Factors affecting the ageing of transformer oil in 150/20 kV transformers", Proceedings of the 17th IEEE International Conference on Dielectric Liquids (ICDL 2011), Trondheim, Norway, June 26-30, 2011

[8] M. G. Danikas, S. Georghiou, I. Liapis, A. B. B. Abd Ghani, "Diagnostic techniques in transformer oils: Factors affecting the lifetime of transformer oil in transformers of $150 / 20 \mathrm{kV}$ and the problem of relating diagnostics data with their pre-history", Funktechnikplus\#Journal, Vol. 1, No. 6, pp. 27-40, 2015.

[9] W. R. Bell, M. G. Danikas, "Factors Affecting the Breakdown Strength of Transformer Oil", Proceedings of IEEE International Symposium on Electrical Insulation, Philadelphia, USA, pp. 264-267, June 1982

[10] N. J. Felici, "Bubbles, partial discharges and liquid breakdown", Electrostatics 79, Institute of Physics Conference Series No. 48, pp. 181190,1979

[11] K. H. Weber, H. S. Endicott, "Area effect and its extremal basis for the electric breakdown of transformer oil", Transactions of American Institute of Electrical Engineers, Vol. 75, pp. 371-381, 1956

[12] H. S. Endicott, K. H. Weber, "Electrode area effect for impulse breakdown of transformer oil", Transactions of American Institute of Electrical Engineers, Vol. 76, pp. 393-398, 1957

[13] N. Giao Trinh, C. Vincent, J. Regis, "Statistical dielectric degradation of large-volume oil-insulation", Transactions on IEEE Power Systems, Vol. 101, No. 10, paper 82 WM 060-2, 1982

[14] J. K. Nelson, "An assessment of the physical basis for the application of design criteria for dielectric structures", IEEE Transactions on Electrical Insulation, Vol. 24, pp. 835-847, 1989

[15] J. K. Nelson, B. Salvage, W. A. Sharpley, "Electric strength of transformer oil for large electrode areas", Proceedings IEE, Vol. 118, No. 2, pp. 388-393, 1971

[16] A. Beroual, M. Zahn, A. Badent, K. Kist, A. J. Schwab, H. Yamashite, K. Yamazawa, M. Danikas, W. G. Chadband, Y. Torshin, "Propagation 
and structure of streamers in liquid dielectrics", IEEE Electrical Insulation Magazine, Vol. 14, No. 2, pp. 6-17, 1998

[17] R. P. Feynman, "There is plenty of room at the bottom", American Physical Society Meeting, 1959

[18] S. U.S. Choi, "Enhancing thermal conductivity of fluids with nanoparticles", in: Developments and Applications of Non-Newtonian Flows, pp. 99-105, New York, 1995

[19] T. Tanaka, "Dielectric nanocomposites with insulating properties", IEEE Transactions on Dielectrics and Electrical Insulation, Vol. 12, pp. 914 928, 2005

[20] T. Tanaka, Personal Communication, February 2018

[21] M. G. Danikas, "On two nanocomposite models: Differences, similarities and interpretational possibilities regarding Tsagaropoulos' model and Tanaka's model", Journal of Electrical Engineering, Vol. 61, No. 4, pp. 241-246, 2010

[22] D. Pitsa, M. G. Danikas, "Interfaces features in polymer nanocomposites: A review of proposed models", NANO, Vol. 6, No. 6, pp. 497-508, 2011

[23] M. G. Danikas, A. Bairaktari, R. Sarathi, A. Basri Bin Abd Ghani, "A review of two nanocomposite materials models: Lewis' contribution in the development of the models, their differences, their similariries and future challenges", Engineering, Technology \& Applied Science Research, Vol. 4, No. 3, pp. 636-643, 2014

[24] G. Melissinos, M. G. Danikas, "On polymers nanocomposites: Electrical treeing, breakdown models and related simulations", Engineering, Technology \& Applied Science research, Vol. 8, No. 2, pp. 2627-2632, 2018

[25] J. Dai, D. Ming, W. Li, Y. Li, J. Wang, "Study on AC breakdown and broadband dielectric response properties of transformer oil-based nanofluids", Proceedings of 2016 International Conference on Condition Monitoring and Diagnosis, Xi'an, China, pp. 24-27, September 25-28, 2016

[26] J. A. Eastman, S. U. S. Choi, S. Li, W. Yu, L. J. Thompson, "Anomalously increased effective thermal conductivities of ethylene glycol-based nanofluids containing copper nanoparticles", Applied Physics Letters, Vol. 78, No. 6, pp. 718-720, 2001

[27] W. Yu, H. Xie, "A Review on Nanofluids: Preparation, Stability Mechanisms and Applications", Journal of Nanomaterials, Vol. 2012, pp. $1-17,2012$

[28] C. H. Lo, T. T. Tsung, L. C. Chen, "Shape-controlled synthesis of Cubased nanofluid using submerged arc nanoparticle synthesis system (SANSS)," Journal of Crystal Growth, Vol. 277, No. 1-4, pp. 636-642, 2005

[29] Y. Du, Y. Lv, C. Li, M. Chen, J. Zhou, X. Li, Y. Zhou, Y. Tu, "Effect of electron shallow trap on breakdown performance of transformer oilbased nanofluids", Journal of Applied Physics, Vol. 110, Issue 10, pp. $104104-1$ - 104104-4, 2011

[30] L. Isaraj, Study of breakdown mechanism in nanofluids, Diploma Thesis, Democritus University of Thrace, Department of Electrical and Computer Engineering, Xanthi, Greece, 2018 (in Greek)

[31] M. Chiesa, S. K. Das, "Experimental investigation of the dielectric and cooling performance of colloidal suspensions in insulating media", Colloids and Surfaces A: Physicochemical Engineering Aspects, Vol. 335, pp. 88-97, 2009

[32] J. Lee, H. Seo, Y. Kim, "The increased dielectric breakdown voltage of transformer-oil based nanofluids by an external magnetic field", International Journal of Thermal Sciences, Vol. 62, pp. 29-33, 2012

[33] J. Lee, W. Kim, "Experimental study on the dielectric breakdown voltage of the insulating oil mixed with magnetic nanoparticles", Physics Procedia, Vol. 32, pp. 327 - 334, 2012

[34] V. Segal, A. Rabinovich, D. Nattrass, K. Raj, A. Nunes, "Experimental study of magnetic colloidal fluids behavior in power transformers", Journal of Magnetism and Magnetic Materials, Vol. 215-216, pp. 513515,2000

[35] J. G. Hwang, M. Zahn, F. M. O’Sullivan, L. A. A. Pettersson, O. Hjortstam, R. Liu, "Electron scavenging of conductive nanoparticles in oil insulated power transformers", 2009 Electrostatics Joint Conference, USA, June 16-18, 2009

[36] J. Lee, W. Lee, S. Lee, S. Lee, "Positive and negative effects of dielectric breakdown in transformer oil based magnetic fluids", Materials Research Bulletin, Vol. 47, pp. 2984-2987, 2012

[37] J. Ghasemi, S. Jafarmadar, M. Nazari, "Effect of magnetic nanoparticles on the lightning impulse breakdown voltage of transformer oil", Journal of Magnetism and Magnetic Materials, Vol. 389, pp. 148-152, 2015

[38] D. H. Fontes, G. Ribatski, E. P. B. Filho, "Experimental evaluation of thermal conductivity, viscosity and breakdown voltage AC of nanofluids of carbon nanotubes and diamond in transformer oil", Diamond and Related Materials, Vol. 58, pp. 115-121, 2015

[39] Y. Zhou, S. Y. Sui , J. Li, Z. Y. Wang, W. Cui, Y. Z. Lv, C. R. Li, "Statistical analysis of moisture's effect on AC breakdown strength of TiO2 nanofluids", Journal of Molecular Liquids, Vol. 249, pp. 420-428, 2018

[40] Y. Zhou, S. Sui, J. Li, Z. Ouyang, Y. Lv, C. Li, W. Lu, "The effects of shallow traps on the positive streamer electrodynamics in transformer oil based nanofluids", Journal of Physics D: Applied Physics, Vol. 51, No. 10,2018

[41] Y. Lv, W. Wang, K. Ma, S. Zhang, Y. Zhou , C. Li, Q. Wang, "Nanoparticle effect on dielectric breakdown strength of transformer oilbased nanofluids", 2013 Annual Report on Conference of Electrical Insulation and Dielectric Phenomena (CEIDP), pp. 680-682, Shenzhen, China, 20-23 October 2013

[42] Y. Lv, M. Rafiq, C. Li, B. Shan, "Study of dielectric breakdown performance of transformer oil based magnetic nanofluids", Energies, Vol. 10, No. 7, Art. No. 1025, 2017

[43] A. Katiyar, P. Dhar, T. Nandi, L. Sirisha Maganti, S. K. Das, "Enhanced dielectric breakdown performance of anatase and rutile titania based nano-oils", IEEE Transactions on Dielectrics and Electrical Insulation, Vol. 23, No. 6, pp. $3494-3503,2016$

[44] F. Negri, Fundamental study and modeling of nanofluids, Ph.D. Thesis, University of Bologna, School of Electrical Engineering, 2017

[45] I. H. Zakaria, M. H. Ahmad, Y. Z. Arief, N. A. Awang, N. A. Ahmad, "Characteristics of mineral oil-based nanofluids for power transformer application", International Journal of Electrical and Computer Engineering (IJECE), Vol. 7, No. 3, pp. 1530-1537, 2017

[46] D. Prasad, S. Chandrasekar, "Investigations on dielectric performance characteristics of natural ester based nano-fluids for power transformer applications", Asian Journal of Research in Social Sciences and Humanities, Vol. 6, No. 11, pp. 1146-1157, 2016

[47] D. Prasad, S. Chandrasekar, "Effect of nano-SiO2 particles on partial discharge signal characteristics of FR3 transtransformer", Journal of Advances in Chemistry, Vol. 13, No. 5, pp. 1-10, 2017

[48] S. Nagendran, S. Chandrasekar, "Investigations on partial discharge, dielectric and thermal characteristics of nano $\mathrm{SiO} 2$ modified sunflower oil for power transformer applications", Journal of Electrical Engineering Technology, Vol. 13, No. 3, pp. 1337-1345, 2018

[49] V. Sridhara, L. N. Satapathy, "Effect of nanoparticles on thermal properties enhancement in different oils - A review", Critical Reviews in Solid State and Materials Sciences, Vol. 40, pp. 99-424, 2015

[50] L. Chetty, I. W. Serukenya, N. M. Ijumba, "Vegetable oil based liquid nanocomposite dielectric", South African Journal of Science, Vol. 109, No. 1, pp. 1-6, 2013

[51] V. A. Primo, B. Garcia , J. Burgos, R. Albarracin, "Enhancing transformer liquid insulation with nanodielectric fluids: State of the art and future trends", Advanced Research Workshop on Transformers, La Toja Island, Spain, October 3-5, 2016

[52] N. Rajan, R. T. Arun Ram Prasath, N. K. Roy, "Ageing performance of mineral oil using $\mathrm{ZnO}$ nanofluids", International Journal of Innovations in Engineering and Technology, Vol. 6, No. 3, pp. 155-162, 2016

[53] O. E. Gouda, A. Thabet, "Experimental verification on enhancing electric and dielectric phenomena of transformer nanofluids", Dielectric Materials and Applications: ISyDMA'2016, Materials Research Proceedings, Vol. 1, pp. 243-246, 2016 
[54] A. Amiri, M. Shanbedi, G. Ahmadi, S. Rozali, "Transformer oils-based graphene quantum dots nanofluid as a new generation of highly conductive and stable coolant", International Communications in Heat and Mass Transfer, Vol. 83, pp. 40-47, 2017

[55] N. S. Suhaimi, M. T. Ishak, M. F. Din, M. M. Ariffin, S. Razali, N. A. Amin, F. R. Hashim, "Breakdown strength of transformer oil filled with carbon nanotubes under various gap distances", Journal of Fundamental and Applied Sciences, Vol. 9, No. 3S, pp. 41-60, 2017

[56] M. F. Dekhordi, Dielectric behavior of transformer oil when contaminated and/or fortified with nanoparticles, M. Sc. Thesis, University of Quebec at Chicoutimi, Canada, 2014

[57] M. M. Hessien, N. A. Sabiha, S. S. M. Ghoneim, A. A. Alahmadi, "Enhancement of dielectric characteristics of transformer oils with nanoparticles", International Journal of Applied Engineering Research, Vol. 12, No. 24, pp. 15668-15673, 2017

[58] S. R. Chitra, S. Sendhilnathan, "Experimental investigations on dielectric fluids behaviour in high-power transformers", International Journal on Applied Ceramic Technology, Vol. 13, No. 6, pp. 1096-1103, 2016

[59] S. R. Chitra, V. Gayathri, "Physical, chemical properties and applications of transformer oil based ferrofluid/dielectric fluid", American Journal of Materials Synthesis and Processing, Vol. 1, No. 4, pp. 47-55, 2016

[60] M. Asefi, H. Molavi, M. Shariaty-Niassar, J. Babaee Darband, N. Nemati, M. Yavari, M. Akbari, "An investigation on stability, electrical and thermal characteristics of transformer insulating oil nanofluids", International Journal of Engineering, Vol. 29, No. 10, pp. 1332-1340, 2016

[61] J. Li, B. Du, F. Wang, W. Yao, S. Yao, "The effect of nanoparticle surfactant polarization on trapping depth of vegetable insulating oilbased nanofluids", Physics Letters A, Vol. 380, pp. 604-608, 2016

[62] M. Rafiq, S. Nazir, "Development of an innovative liquid insulation system for transformers", Contemporary Research in Science and Technology, Vol. 1, No. 1, pp. 47-55, 2016

[63] M. Dong, J. Dai, Y. Li, J. Xie, M. Ren, Z. Dang, "Insight into the dielectric response of transformer oil-based nanofluids", AIP Advances, Vol. 7, pp. 025307-1 - 025307-7, 2017

[64] M. S. Mohamad, H. Zainuddin, S. Ab Ghani, I. S. Chairul, "AC breakdown voltage and viscosity of palm fatty acid ester (PFAE) oilbased nanofluids", Journal of Electrical Engineering and Technology, Vol. 12, No. 6, pp. 2333-2341, 2017

[65] M. Nazari, M. H. Rasoulifard, H. Hosseini, "Dielectric breakdown strength of magnetic nanofluid based on insulation oil after impulse test”, Journal of Magnetism and Magnetic Materials, Vol. 399, pp. 1-4, 2016

[66] C. Cely, N. Koditwuakku, O. Nogueira, "Breakdown features of transformer oil based magnetic nanofluids", Bulletin of Petroleum Production Technology, Vol. 12, No. 3, pp. 7-13, 2017

[67] F. M. O'Sullivan, A model for the initiation and propagation of electrical streamers in transformer oil and transformer oil based nanofluids, Ph.D. Thesis, MIT, Boston, USA, 2007

[68] A. Fallah-Shojaie, A. Tavakoli, M Ghomashpasand, S Hoseinzadeh, "Experimental evaluation on the dielectric breakdown voltage of fresh and used transformer oil mixed with titanium dioxide nanoparticles in the Gilan Electrical distribution company", Proceedings of $201321^{\text {st }}$ Iranian Conference on Electrical Engineering (ICEE), Mashhad, Iran, May 14-16, 2013

[69] D. A. Mansour, E. G. Atiya, R. M. Khattab, A. M. Azmy, "Effect of titania nanoparticles on the dielectric properties of transformer oil-based nanofluids", 2012 Annual Report on Electrical Insulation and Dielectric Phenomena (CEIDP), pp. 295-298, Montreal, Canada, October 14-17, 2012

[70] E. G. Atiya, D. A. Mansour, R. M. Khattab, A. M. Azmy, "Dispersion behavior and breakdown strength of transformer oil filled with $\mathrm{TiO} 2$ nanoparticles", IEEE Transactions on Dielectrics and Electrical Insulation, Vol. 22, No. 5, pp. 2463-2472, 2015

[71] C. Olmo, I. Fernández, F. Ortiz, C. J. Renedo, S. Pérez, "Dielectric properties enhancement of vegetal transformer oil with $\mathrm{TiO} 2, \mathrm{CuO}$ and
$\mathrm{ZnO}$ nanoparticles", Proceedings of International Conference on Renewable Energies and Power Quality (ICREPQ'18), pp. 623-627, Salamanca, Spain, March 21-23, 2018,

[72] C. F. Diego, A. Santisteban, F. O. Fernández, F. Delgado, A. Ortiz, "Effect of $\mathrm{TiO} 2$ nanoparticles on the performance of a natural ester dielectric fluid", Proceedings of 2017 Electrical Insulation Conference (EIC), Baltimore, USA, June 11 - 14, 2017

[73] W. Saenkhumwong, A. Suksri, "The improved dielectric properties of natural ester oil by using $\mathrm{ZnO}$ and $\mathrm{TiO} 2$ nanoparticles", Engineering and Applied Science Research, Vol. 44, No. 3, pp. 148-153, 2017

[74] B. X. Du, X. L. Li, "Dielectric and thermal characteristics of vegetable oil filled with BN nanoparticles", IEEE Transactions on Dielectric and Electrical Insulation, Vol. 24, No. 2, pp. 956- 963, 2017

[75] B. Du, J. Li, F. Wang, W. Yao, S. Yao, "Influence of monodisperse Fe3O4 nanoparticle size on electrical properties of vegetable oil-based nanofluids", Journal of Nanomaterials, Art. No. 560352, 2015

[76] G. D. Peppas, A. Bakandritsos, V. P. Charalampakos, E. C. Pyrgioti, J. Tucek, R. Zboril, I. F. Gonos, "Ultrastable Natural Ester-Based Nanofluids for High Voltage Insulation Applications", ACS Applied Materials and Interfaces, Vol. 8, pp. 25202-25209, 2016

[77] K.Sindhuja, M. Srinivasan, N. Niveditha, "Natural esters as an alternative to mineral oil in transformer applications", International Journal of Pure and Applied Mathematics, Vol. 118, No. 20, pp. 723731,2018

[78] H. Kojima, T. Kondo, M. Hanai, N. Hayakawa, "Improvement mechanism of AC breakdown voltage of insulating oil with dispersed nanoparticles", Electronics and Communications in Japan, Vol. 100, No. 12, pp. 101-106, 2017

[79] Huifei Jin, Dielectric strength and thermal conductivity of mineral oil based nanofluids, Ph.D. Thesis, Delft University of Technology, The Netherlands, 2015

[80] J. Kudelcik , P. Bury, P. Kopcansky, M. Timko, "Dielectric breakdown in mineral oil ITO 100 based magnetic fluid", Physics Procedia, Vol. 9, pp. 78-81, 2010

[81] Y. Jing, Breakdown properties of mineral oil and ester based $\mathrm{TiO} 2$ and BN nanofluids, Ph.D. Thesis, University of Strathclyde, Department of Electronic and Electrical Engineering, Glasgow, UK, 2016

[82] M. Srinivasan, U.S. Ragupathy, K. Sindhuja, A. Raymon, "Investigation and performance analysis of nanoparticles and antioxidants based natural ester", International Journal of Advanced Engineering Technology, Vol. VII, No. 11, pp. 1000-1007, 2016

[83] M. Taro, D. Shill, A. Kumar Das, S. Chatterjee, "Experimental investigation of transformer oil based nanofluids for applications in distribution transformers", Proceedings of $20173^{\text {rd }}$ International Conference on Condition Assessment techniques in Electrical Systems (CATCON), pp. 367-370, 2017

[84] J. A. Mergos, M. D. Athanassopoulou, T. G. Argyropoulos, C. T. Dervos, "Dielectric properties of nanopowder dispersions in paraffin oil", IEEE Transactions on Dielectrics and Electrical Insulation, Vol. 19, No. 5, pp. 1502-1507, 2012

[85] A. R. P. R. Thirugnanam, W. I. M. Siluvairaj, I. K. Radha, "Retreatment of aged mineral oil using semiconductive nanocomposites for power transformer application", International Transactions on Electric Energy Systems, Vol. 27, 2017

[86] S. S. Dessouky, S. A. M. Abdelwahab, M. Shaban, "Affecting factors titanium oxide of nanoparticles for the electrical effect on insulation resistance of the transformer oil", International Research Journal of Electronics and Computer Engineering, Vol. 3, No. 4, pp. 22-27, 2017

[87] P. Thomas, N. E. Hudedmani, "AC breakdown voltage characteristics of synthetic ester based egg shell nanofluids", Proceedings of $20173^{\text {rd }}$ International Conference on Condition Assessment Techniques in Electrical Systems (CATCON), pp. 112-115, Rupnagar, India, 16-18 November 2017

[88] S. Aberoumand, A. Jafarimoghaddam, "Tunsten (III) oxide (WO3) silver/transformer oil hybrid nanofluid: Preparation, stability, thermal conductivity and dielectric strength", Alexandria Engineering Journal, Vol. 57, pp. 169-174, 2018 
[89] R. Karthik, T. Sree Renga Raja, R. Madavan, "Enhancement of critical characteristics of transformer oil using nanomaterials", Arabian Journal for Science and Engineering, Vol. 38, pp. 2725-2733, 2013

[90] I. L. Hosier, A. S. Vaughan, "Effect of particulates on the dielectric properties and breakdown strength of insulation oil", Proceedings of the 2017 IEEE Electrical Insulation Conference (EIC 2017), Baltimore, Maryland, USA, June 11-14, 2017

[91] M. Bhatt, "Effect of permittivity on breakdown characteristic of transformer oil based nanofluid", International Journal of Trend in Scientific Research and Development, Vol. 2, No. 3, pp. 262-266, 2018

[92] P. Zou, J. Li, C. Sun, Z. Zhang, R. Liao, "Dielectric properties and electrodynamic process on natural ester- based insulating nanofluid", Modern Physics Letters B, Vol. 25, No. 25, pp. 2012-2031, 2011

[93] K. Swati, R. Sarathi, K. S. Sharma, "Understanding the surface discharge activity with Thermally Aged Nanofluid Impregnated Paper Insulating Material", International Journal on Electrical Engineering and Informatics, Vol. 9, No. 4, pp. 762-775, 2017

[94] S. Ab Ghani , N. Asiah Muhamad, Z. Ahmad Noorden, H. Zainuddin, N. Abu Bakar, M. Aizam Talib, "Methods for improving the workability of natural ester insulating oils in power transformer applications: A review", Electric Power Systems Research, Vol. 163, Part B, pp. 655667,2018

[95] R. Taylor, S. Coulombe, T. Otanicar, P. Phelan, A. Gunawan, W. Lv, G. Rosengarten, R. Prasher, H. Tyagi, "Small particles, big impacts: A review of the diverse applications of nanofluids", Journal of Applied Physics, Vol. 113, 011301-1 - 011301-19, 2013 